\title{
Microarray-based Analysis of Genes, Transcription Factors, and Epigenetic Modifications in Lung Cancer Exposed to Nitric Oxide
}

\author{
ARNATCHAI MAIUTHED ${ }^{1}$, ORNJIRA PRAKHONGCHEEP ${ }^{2,3}$ and PITHI CHANVORACHOTE ${ }^{2,3}$ \\ ${ }^{1}$ Department of Pharmacology, Faculty of Pharmacy, Mahidol University, Bangkok, Thailand; \\ ${ }^{2}$ Cell-based Drug and Health Product Development Research Unit, \\ Faculty of Pharmaceutical Sciences, Chulalongkorn University, Bangkok, Thailand; \\ ${ }^{3}$ Department of Pharmacology and Physiology, Faculty of Pharmaceutical Sciences, \\ Chulalongkorn University, Bangkok, Thailand
}

\begin{abstract}
Background/Aim: Nitric oxide (NO) is recognized as an important biological mediator that exerts several human physiological functions. As its nature is an aqueous soluble gas that can diffuse through cells and tissues, NO can affect cell signaling, the phenotype of cancer and modify surrounding cells. The variety of effects of NO on cancer cell biology has convinced researchers to determine the defined mechanisms of these effects and how to control this mediator for a better understanding as well as for therapeutic gain. Materials and Methods: We used bioinformatics and pharmacological experiments to elucidate the potential regulation and underlying mechanisms of NO in non-small a lung cancer cell model. Results: Using microarrays, we identified a total of 151 NO-regulated genes (80 upregulated genes, 71 down-regulated genes) with a strong statistically significant difference compared to untreated controls. Among these, the genes activated by a factor of more than five times were: DCBLD2, MGC24975, RAB40AL, PER3, RCN1, MRPL51, PTTG1, KLF5, NFIX. On the other hand, the expression of RBMS2, PDP2, RBAK, ORMDL2, GRPEL2, ZNF514, MTHFD2, POLR2D, RCBTB1, JOSD1, RPS27, GPR4 genes were significantly decreased by a factor of more than five times. Bioinformatics further revealed that
\end{abstract}

This article is freely accessible online.

Correspondence to: Associate Professor Dr. Pithi Chanvorachote, Department of Pharmacology and Physiology, Faculty of Pharmaceutical Sciences, Chulalongkorn University, 254 Phayathai Road, Pathumwan, Bangkok 10330, Thailand. Tel: +66 22188344, e-mail: pithi.c@chula.ac.th; pithi_chan@yahoo.com

Key Words: Nitric oxide, microarrays, bioinformatics, transcription factors, epigenetic modifications, lung cancer.
NO exposure of lung cancer cells resulted in a change in transcription factors (TFS) and epigenetic modifications (histone modification and miRNA). Interestingly, NO treatment was shown to potentiate cancer stem cell-related genes and transcription factors Oct4, Klf4, and Myc. Conclusion: Through this comprehensive approach, the present study illustrated the scheme of how NO affects molecular events in lung cancer cells.

Lung cancer is one of the leading causes of cancer-related deaths worldwide $(1,2)$. Since the aggressive phenotypes and treatment failures have been frequently observed in lung cancer patients (3-5), researchers are currently focusing on research for novel therapeutic targets towards development of more precise therapeutic options.

The impact of the cancer microenvironment in progression of the disease has been well established (6). Nitric oxide (NO), one of the most recognized substances in the microenvironment, is frequently up-regulated in certain cancers including lung cancer (7-9). NO is a short-lived gas that is endogenously produced by several cells in the human body. It is synthesized from arginine by a group of enzymes named nitric oxide synthases (NOS) $(10,11)$. Although it is known that a substantial amount of NO can regulate normal physiological activities such as vasodilation and neurotransmission, the dysregulation or excessive production of NO contributes to pathophysiological conditions. Indeed, high NOS expression has been detected in many cancers including breast, cervical, head and neck, central nervous system, and lung cancers (9-12). NO has been linked to cancers and has been proposed to have dual effects $(13,14)$. Several studies have revealed that NO promotes tumor growth and progression at low and moderate concentrations $(6,7,9)$. On other hand, NO at high concentrations could exert a cancer cell killing effect $(15,16)$. In lung cancer, NO 
has been shown to mediate aggressive cancer phenotypes in terms of migration and invasion (17), anoikis resistance (18), chemotherapeutics drugs resistance (19), and cancer stem cell-like behaviors $(20,21)$. Despite the fact that the current known molecular signaling pathways of NO are insufficient to explain all its activities in cancer biology, the highthroughput technology with global database, such as microarrays and bioinformatics, would be a useful tool to provide a better understanding of the effects of NO and aid in search for novel cancer drug targets that are affected by NO. Bioinformatics has become an important tool for molecular biology studies, especially regarding interpretation of microarray data (22). Although a microarray can provide a vast amount of biological information, the direct output of microarrays cannot be used without appropriate analysis by a database analytical tool (23). Bioinformatics utilizes biological data from various validated sources and provides valuable data sets, including potential transcription factors and epigenetics modifications, suggested cellular pathways, and the ontology of gene expression (24).

Using the Affymetrix microarray, we determined the gene expression pattern in response to NO treatment. Bioinformatics analysis further described the NO-regulated genes, focusing on the transcription factors (TFs) and epigenetics modifications (histone modification and miRNA). Paying considerable attention to the molecular effects of NO on cancer cells will remove certain discrepancies in the field of knowledge and facilitate a great in-depth understanding of how this important biological regulator controls cancer cells.

\section{Materials and Methods}

Cells and reagents. Human non-small cell lung cancer cell line, H460, was obtained from the American Type Culture Collection ATCC (Manassas, VA, USA). The cells were cultured in RPMI1640 medium with $10 \%$ fetal bovine serum, $2 \mathrm{mM} \mathrm{L-glutamine,} \mathrm{and}$ $100 \mathrm{U} / \mathrm{ml}$ of penicillin and streptomycin $(\mathrm{GibCo})$ in $5 \% \mathrm{CO}_{2^{-}}$ humidified incubator under $37^{\circ} \mathrm{C}$. Cells were routinely sub-cultured at $70 \%$ confluent density using a $0.25 \%$ trypsin solution with 0.53 mM EDTA. Nitric oxide (NO) donor, dipropylenetriamine (DPTA) NONOate, was purchased from Santa Cruz Biotechnology (Santa Cruz, CA, USA). Previous studies showed that DPTA (NO donor) was relatively non-toxic to non-small cell lung cancer cell lines (17, $21,25)$, and the non-toxic concentration for $\mathrm{H} 460$ cells were $0-50$ $\mu \mathrm{M}$. In this study, $10 \times 10^{4}$ cells of $\mathrm{H} 460$ were seeded overnight and treated with $40 \mu \mathrm{M}$ of DPTA for 5 days (the freshly prepared DPTA was replace every day). Treated and untreated control cells were subjected to gene expression analysis.

Microarray analysis. After specific treatment, the cells were collected. The mRNA of two independent experiments were harvested and cDNA was prepared according to the Affymetrix's protocol. In brief, $10 \mu \mathrm{g}$ of total RNA was reverse transcribed using SuperScript II RT (Invitrogen, CA, USA) and T7-(dT)24primer. After double-strand cDNAs were created, the cDNAs were purified and precipitated by phenol-chloroform extraction/ethanol precipitation. The cDNAs were subjected to synthesis biotin-labelled cRNA and quantified by a NanoDrop-1000. Fifteen micrograms of cRNA were used to make $300 \mu$ of hybridization cocktail. A total of $225 \mu \mathrm{l}$ of the cocktail were used for target hybridization on the gene chip as Affymetrix's procedure. After washing, slides were scanned in an Agilent GeneArray Scanncer (Agilent, CA, USA).

Biological process analysis. The 151 NO-regulated genes were subjected to String (https://string-db.org/) to predict cell biological processes mediated by NO. This result was analyzed by date $20^{\text {th }}$ September 2019.

Prediction of potential transcription factors. The 151 NO-mediated genes were analyzed by Enrichr (http://amp.pharm.mssm.edu/Enrichr/) for determining the transcription factors that could control the expression of these genes. We analyzed the NO-mediated genes with Enrichr using gene set libraries as follows: ChIP enrichment analysis (ChEA) (https://genome.ucsc.edu/ENCODE/), Enrichr for ProteinProtein Interactions (PPIs) (http://amp.pharm.mssm.edu/Enrichr/, encyclopedia of DNA elements (ENCODE) TF ChIP-seq 2015 (https://genome.ucsc.edu/ENCODE/), TRANSFAC and JASPAR PWMs (http://genexplain.com/transfac/ and http://jaspar.genereg.net/), Enrichr Submission TF-Gene co-occurrence (http://amp.pharm. mssm.edu/Enrichr/), ENCODE and ChEA consensus TFs from ChIP$\mathrm{X}$ (https://genome.ucsc.edu/ENCODE/), and ARCHS4 TFs (https: //amp.pharm.mssm.edu/archs4/). The visualization of transcription factors hub networks and the calculation of p-value, odds ratio (OR), and combined scores were constructed by Enrichr (http: //amp.pharm.mssm.edu/Enrichr/). The results were analyzed by date $20^{\text {th }}$ September 2019.

Screening of potential epigenetic modifications. Histone modifications and epigenetic alterations mediated by NO were analyzed by Enrichr (http://amp.pharm.mssm.edu/Enrichr/). We investigated the histone modification and potential miRNA with Enrichr using gene set libraries as follows: ENCODE histone modifications 2015 (https://genome.ucsc.edu/ENCODE/), TargetScan microRNA2017 (http://www.targetscan.org/vert_72/), and miTarBase2017 (http://miRTarBase.mbc.nctu.edu.tw). The visualization of histone modification hub networks and the calculation of $p$-value, $\mathrm{OR}$, and combined score were constructed by Enrichr. The results were analyzed by date $20^{\text {th }}$ September 2019 .

Statistical analysis. The mRNA expression levels of two independent experiments were analyzed by the two-tailed Student's $t$-test to compare mean expression levels and identify NO-specific genes. All statistical analysis processes were performed by Connection Up- and Down-Regulation Expression of Microarrays (CU-DREAM) software (26). Statistical significance was set at $p<0.05$. The $151 \mathrm{NO}$-mediated genes that were strongly statistically altered between control and treatment groups $(p<0.01)$ were subjected to examine for potential transcription factors, histone modification, and miRNA by bioinformatic databases.

\section{Results}

Identification of NO-affected genes in non-small lung cancer cells. Two independent sets of NSCLC H460 cells were continuously exposed to NO donor (DPTA NONOate) at 
Table I. Genes that were significantly altered by nitric oxide treatment.

\begin{tabular}{|c|c|}
\hline Effect of NO on genes expression & Gene names \\
\hline Up-regulated genes expression & $\begin{array}{l}\text { PER3, MRTO4, FAM167B, ZNF362, CELSR2, S100A1, SNAPIN, SNRPE, SNIP1, CASQ2, OR6P1, GCSH, } \\
\text { RCN1, RHOG, OR5B17, C11orf75, THY1, GPD1, RPS26, MYL6B, INHBC, TRHDE, TNFRSF1A, MRPL51, } \\
\text { GALNT6, IL17D, KLF5, LAMP1, OR10G2, CMTM2, G6PC, MYH3, UBE2S, AATK, COLEC12, HMG20B, } \\
\text { NFIX, CD3EAP, MGC24975,FBXL12, LGI4, FLJ32063, FBXO48, KRTAP19-8, C21orf77, DSCR4, } \\
\text { ICOSLG, PDXP, ARGFX, COL29A1, C3orf75, DCBLD2, STAG1, HTN1, CDS1, HSPA4L, PPBP, CENPE, } \\
\text { FLJ37543, PTTG1, TAF7, FTSJD2, RFPL4B, PLN, FAM164B, MAS1, PRRT1, VWC2, EPHB6, CRIM2, } \\
\text { NUDT18, SFRP1, SURF6, RAB40AL, HPRT1, SAGE1, KLHL34, GUCY2F, MAGEA1, RBMY1B }\end{array}$ \\
\hline Down-regulated genes expression & $\begin{array}{l}\text { RPL11, RPS27, KCTD3, SDCCAG8, ARL5B, PSTK, PRKCQ, PLAC1L, ASB9, CEP164, ORMDL2, RBMS2, } \\
\text { C12orf45, KNTC1, BRI3BP, NRIP2, WBP11, CCDC59, RCBTB1, SERPINA3, CCDC88C, LOC646358, } \\
\text { NDUFB10, OR2C1, PDP2, POLR3K, RPS2, ICT1, KIAA1328, PIK3C3, YIPF2, GPR4, MTHFD2, } \\
\text { ARHGAP15, ZNF514, ERCC3, POLR2D, BAZ2B, INO8OD, CHMP4B, CTA-221G9.4, GRAP2, JOSD1, } \\
\text { GFM1, SENP2, FYCO1, BCHE, KCNMB3, UGT2B7,GRPEL2, HMGXB3, ZNF354B, DDX41, IRAK1BP1, } \\
\text { FAM46A, SRrp35, RBAK, LOC255374, PRSS1, OR6V1, CLDN23, HSF1, LONRF1, KCTD9, MRPS2, MAN1B1, } \\
\text { RLN1, ZNF782, PLP2, EFNB1, SASH3 }\end{array}$ \\
\hline
\end{tabular}

non-cytotoxic concentration $(40 \mu \mathrm{M})$ for 5 days. NO-treated cells and their non-treated counterparts were subjected to cDNA preparation and analyzed for gene expression by microarrays, as described in Materials and Methods. After using the CU-DREAM program to analyze the raw data, the 151 gene lists with a strong significant difference $(p<0.01)$ were selected for the next interpretation, as listed in Table I.

Analysis for nitric oxide-mediated biological process alteration. The statistically significantly differentially expressed 151 NO-mediated genes were subjected to search tool for the retrieval of interacting genes/proteins (String) software for determination NO-altered biological processes. The results from the String analysis showed various cellular biological processes altered by NO exposure (data not shown). We analyzed the effects of NO on the biological processes that would usually be changed in cancer such as gene expression control (52/151 genes), ribonucleoprotein complex biogenesis (11/151 genes), regulation of translation (14/151 genes), protein targeting to endoplasmic reticulum (ER) (10/151 genes), and cellular metabolic processes (90/151 genes). Figure 1 shows protein-protein association by line-color and shows the function of proteins in each biological process by node-color. The biological process that was mostly altered by NO exposure was the cellular metabolic process $(90 / 151$ genes $)$, represented by the green node.

The second ranking process was the gene expression process $(52 / 151$ genes) which is shown by the blue node. Interestingly, the NO-regulated genes with a high degree of connection lines have multitudinous functions in controlling of biological processes, as represented by multicolor node network in the center of diagram. The other network group of input genes was mainly involved in the regulation of cellular metabolism, gene expression and RNA processing through controlling ribonucleoprotein complex biogenesis. The node proteins of this network group were POLR2D, SNRPE, and POLR3K.

Screening for potential transcription factors. The 151 genes with a significant difference were used to predict the potential transcription factors using the web-based bioinformatics tool, Enrichr. The results from this analysis showed the top ten potential transcription factors together with their $p$-value, OR, combined score, and the target genes of the transcription factor that matched with the input genes. The potential transcription factors were arranged by a combined score. The results from certain gene set libraries were recorded as follows:

ChEA 2016. Data from the ChEA 2016 gene set database showed that many potential transcription factors were responsible for NO-mediated gene alteration. For a better understand, the top ten transcription factors with high combined scores are shown in Table II, namely; STAT3, ZNF652, ETS1, MYC, TFAP2A, PRDM16, JARID1A, OCT4, SALL4, and Sox2. The networks of hub transcription factors arranged by p-value, namely KLF4, ETS1, E2A, OCT4, MYC, MAF, TOP2B, SALL4, TFAP2A, and JARID1A are shown in Figure 2A. From Figure 2(A) the hub with the highest number of linkage was OCT4.

ENCODE transcription factor (TF)-ChIP-sequences 2015. The top ten transcription factors ranked by combined score using ENCODE TF ChIP-seq 2015 gene set library were CUX1, FOXM1, RFX5, RAD21, SMC3, EBF1, TAF1, ELK1, CREB1, and EBF1, as shown in Table III. However, transcription factor hub analysis by $p$-value demonstrated 


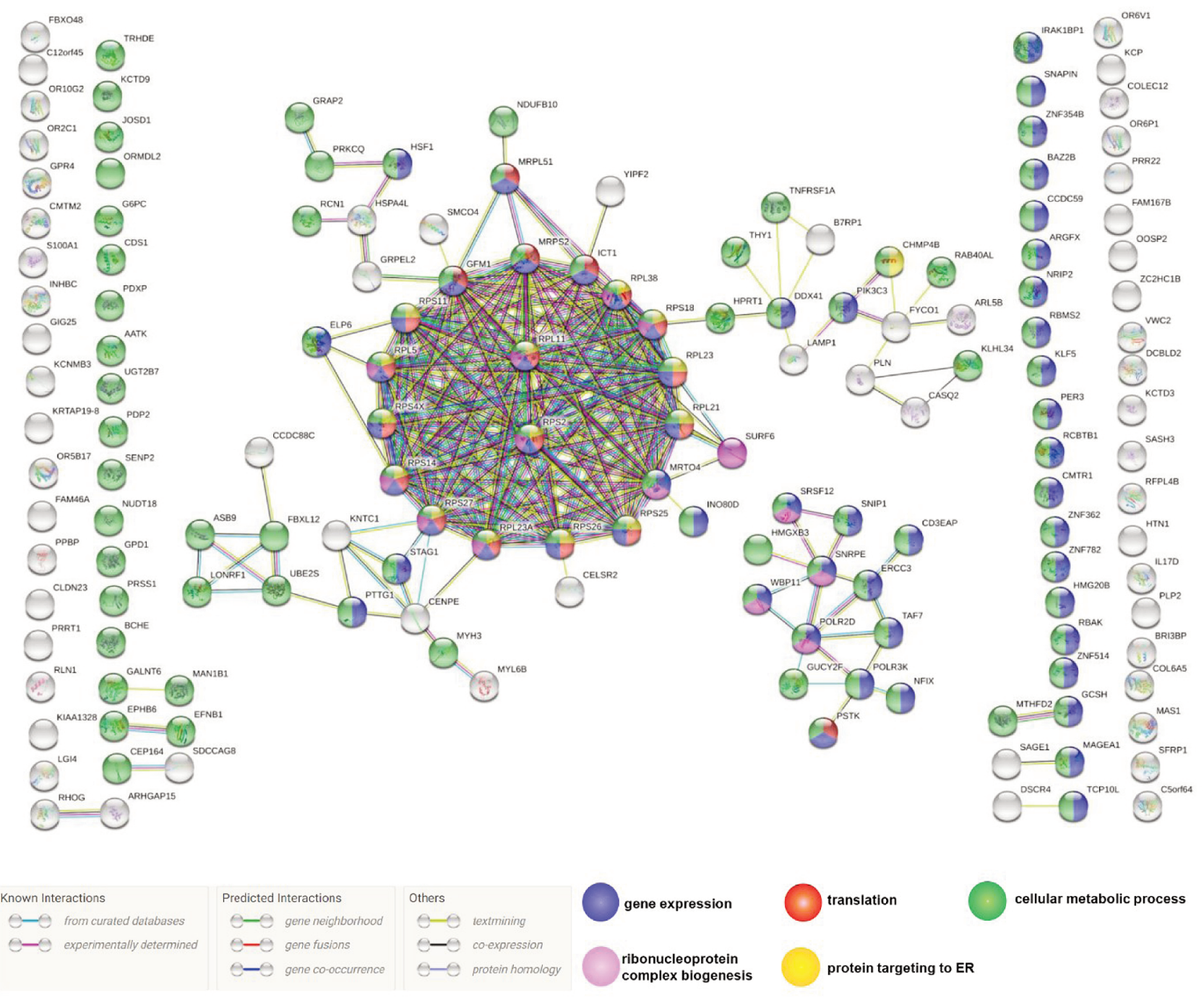

Figure 1. Pathway analysis by String. The 151 NO-regulated genes were subjected to String for analyzing the pathways regulated by NO.

that TRIM28 was the factor with the highest number of connection lines with other transcription factors (Figure 2B).

Protein-protein interaction (PPI) network. The top ten enriched transcription factors for the target genes of NOtreated factors from PPI gene set analysis ranged by combined score were: SIX5, ILF2, MEF2A, SMAD2, ZBTB7B, NR2F2, TBP, ILF3, RARA, and USF as shown in Table IV. For the network transcription factor interaction, the highest-ranking linked hub was TBP, as shown in Figure 2C.

Transcription factor database (TRANSFAC) and JASPAR position-specific weight matrices ( $P W M S$ ). Analysis of the NO-mediated 151 genes alteration by TRANSFAC and JASPAR PWMs gene set libraries gave the top ten factors ranked by combined score as ESR2, RARA, JDP2, NR1H2,
FOXA1, SND1, FOXO3A, Myb, IRF1, and ELK1, as listed in Table V. Moreover, the database also provided the transcription factors hub linkage displayed in Figure 2D. This result showed that RARA has the highest number of network lines compared to other transcription factors.

Enrichr submission transcription factor-gene co-occurrence. This analysis gave the top ten potential transcription factors ranked by combined score, as listed in Table VI (ZNF593, CPSF4, ZNF511, BOLA3, HMGB3, PRMT3, THAP11, YEATS4, ZMAT2, and ZNF121).

ENCODE and ChEA consensus TFs from ChIP-X. The results showed the ranking of transcription factors by combined score as CBX3, FOXM1, ATF2, SALI4, MAX, KAT2A, IRF3, POU5F1, NR2C2, and PPARG (Table VII). 
Table II. The ChEA 2016 top ten enriched transcription factors affected by DPTA NONOate.

\begin{tabular}{|c|c|c|c|c|}
\hline Transcription factors & $p$-Value & OR & $\begin{array}{l}\text { Combined } \\
\text { score }\end{array}$ & $\begin{array}{l}\text { Targeted genes from } \\
\text { input genes }\end{array}$ \\
\hline STAT3_22323479_ChIP-Seq_MACROPHAGE_Mouse & 0.033338 & 6.97 & 23.71 & CCDC59; MRPS2 \\
\hline ZNF652_21678463_ChIP-ChIP_ZR75-1_Human & 0.05303 & 3.55 & 10.42 & CENPE; STAG1; TNFRSF1A \\
\hline ETS1_20019798_ChIP-Seq_JURKAT_Human & 0.004653 & 1.81 & 9.74 & $\begin{array}{c}\text { ZNF782; GFM1; SNAPIN; NDUFB10; RPL11; } \\
\text { CCDC59; FBXO48; MYL6B; DDX41; RPS26; } \\
\text { FYCO1; RPS27; LAMP1; MRTO4; SNIP1; } \\
\text { CHMP4B; C3ORF75; SURF6; SNRPE; } \\
\text { PIK3C3; SDCCAG8; ZNF354B }\end{array}$ \\
\hline MYC_18940864_ChIP-ChIP_HL60_Human & 0.011105 & 2.13 & 9.59 & $\begin{array}{c}\text { CDS1; KCTD9; RPS27; GRPEL2; CLDN23; } \\
\text { POLR2D; FAM46A; CD3EAP; RLN1; } \\
\text { BRI3BP; MGC24975; FBXL12 }\end{array}$ \\
\hline TFAP2A_17053090_ChIP-ChIP_MCF-7_Human & 0.004367 & 1.74 & 9.45 & $\begin{array}{c}\text { COLEC12; SERPINA3; OR2C1; NFIX; } \\
\text { CEP164; AATK; GUCY2F; RCBTB1; EFNB1; } \\
\text { GRAP } 2 \text {; NRIP } 2 ; \text { MAGEA1; OR5B17; LGI4; } \\
\text { WBP11; JOSD1; TNFRSF1A; MRPL51; MYH3; } \\
\text { UBE2S; ASB 9; CHMP4B; HPRT1; CMTM2; RBMS2 }\end{array}$ \\
\hline $\begin{array}{l}\text { PRDM16_22522345_ChIP-ChIP_- } \\
\text { PALATE_MESENCHYMAL_Mouse }\end{array}$ & 0.065124 & 3.26 & 8.90 & GALNT6; LONRF1; TRHDE \\
\hline JARID1A_20064375_ChIP-Seq_MESCs_Mouse & 0.006295 & 1.65 & 8.35 & $\begin{array}{c}\text { GFM1; NDUFB10; MYL6B; DDX41; LAMP1; } \\
\text { ICT1; ORMDL2; GRPEL2; SNIP1; SURF6; } \\
\text { RPS2; YIPF2; CCDC59; MRPS2; KCTD3; WBP11; } \\
\text { SENP2; FBXL12; KCTD9; ERCC3; MRTO4; } \\
\text { GPD1; TAF7; PIK3C3; MAN1B1; RBAK; POLR } 3 K\end{array}$ \\
\hline OCT4_19829295_ChIP-Seq_ESCs_Human & 0.008089 & 1.66 & 7.98 & $\begin{array}{l}\text { SASH3; COLEC12; GFM1; HSPA4L; DDX41; } \\
\text { LAMP1; GRAP2; MAGEA1; C3ORF75; KNTC1; } \\
\text { HMGXB3; OR5B17; MRPS2; JOSD1; FBXL12; } \\
\text { RPS26; STAG1; MRPL51; MYH3; PER3; } \\
\text { MTHFD2; UBE2S; CASQ2; SNRPE; RAB4OAL }\end{array}$ \\
\hline SALL4_18804426_ChIP-ChIP_XEN_Mouse & 0.020018 & 1.85 & 7.22 & $\begin{array}{c}\text { S100A1; LGI4; GPR4; RCBTB1; KCTD9; } \\
\text { EFNB1; STAG1; RCN1; PLN; KLF5; } \\
\text { CASQ2; CHMP4B; TAF7; RBMS2 }\end{array}$ \\
\hline SOX2_18555785_ChIP-Seq_MESCs_Mouse & 0.035175 & 2.13 & 7.14 & $\begin{array}{l}\text { RPS26; STAG1; GRAP2; GRPEL2; } \\
\text { CASQ2; KLHL34; PRKCQ; FBXL12 }\end{array}$ \\
\hline
\end{tabular}

OR: Odds ratio.

ARCHS4 TFs. Analysis using the gene set from ARCHS4 TFs library showed the top ten transcription factors ranked by combined score were KLF15, ZNF528, MYF6, ZBED1, PRDM15, GPR155, SOX10, POU6F2, ELK3, and NPAS1 as presented in Table VIII.

Screening for potential miRNA and histone modifications. The 151 NO-mediated genes with a strong difference between treated and untreated groups were used to predict the epigenetic alteration effects from NO exposure using the web-based bioinformatic tool, Enrichr, as described in Material and Methods. The results from these analysis tools showed the top ten suggested histone modifications and potential miRNA together with $p$-value, OR, combined score, and target gene of the transcription factor that matched with the input genes. The results were arranged by their combined score.
ENCODE histone modifications 2015. As gene alterations may occur by the modification of certain histone proteins, the activity of NO might rely on this cellular process. To evaluate the potential histone modifier effect of NO, 151 genes mediated by NO were analyzed using ENCODE histone modification database version 2015. The results are shown in Table IX, revealing that the top ten ranking according to combined score were: H3K79me3, H3K9me1, H3K79me2, H2AFZ, H3K36me3, H3K27ac, K4K20me1, H3K9ac, H3K79me2, and H3K36me3. The histone modification network analysis was conducted, and it was found that $\mathrm{H} 3 \mathrm{~K} 36 \mathrm{me} 3$ was the hub histone modification with the highest connectivity degree (Figure 3 ).

TargetScan microRNA2017. miRNA is the non-coding RNA that controls the expression of coding mRNA by regulating its half-life. The TargetScan microRNA database version 2017 was used for determining the potential miRNAs altered 
A

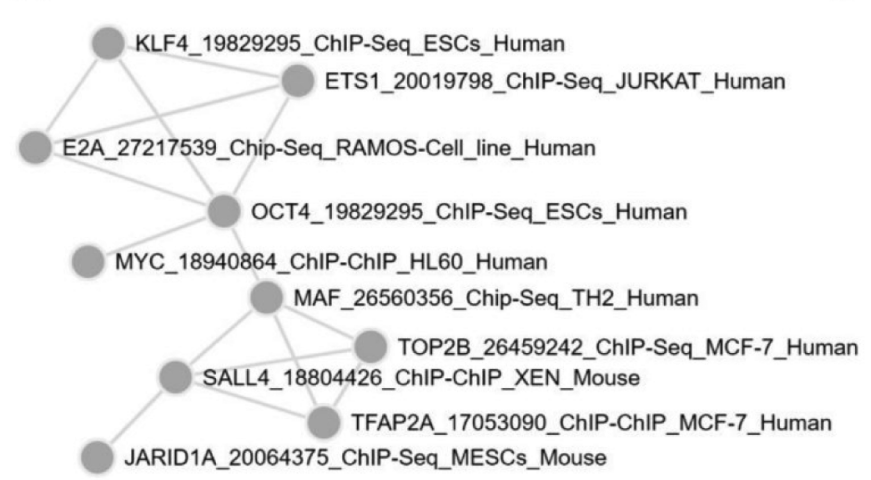

B

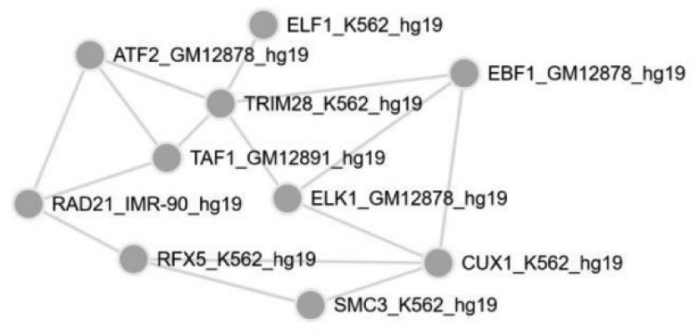

C
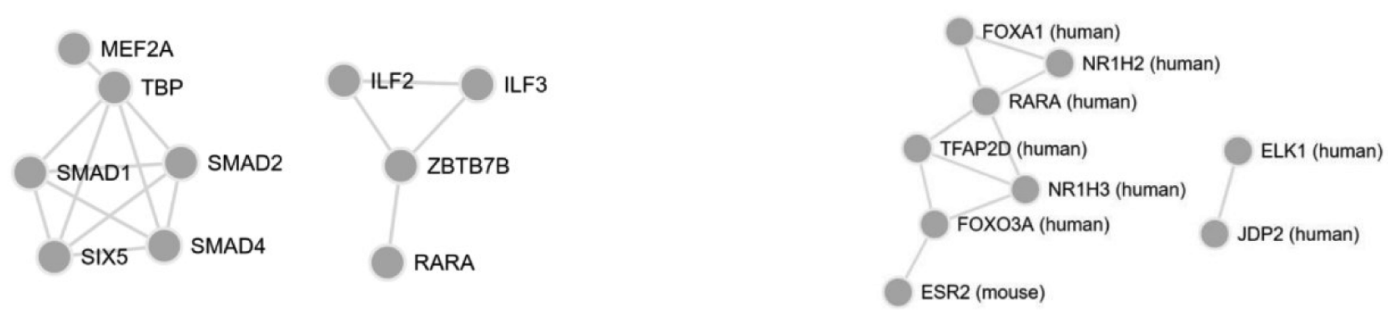

Figure 2. Potential transcription factor network. (A) Network from ChEA2016. (B) Network from ENCODE TF ChIP-seq 2015. (C) Network from Transcription Factor PPI. (D) Network from TRANSFAC and JASPAR PWMs.

by NO treatment (Table $\mathrm{X}$ ). The analysis revealed hsa-miR4749-5p, hsa-miR-4706, hsa-miR-615-3p, mmu-miR-3072, hsa-miR-28-3p, mmu-miR-187, mmu-miR-695, hsa-miR4781-5p, hsa-miR-572, and mmu-miR-1947 as the top ten results.

miTarBase2017. The results from Enrichr using the miTarBase version 2017 data library revealed the suggested miRNA ranked by combined score as the following: mmumiR-292a-3p, mmu-miR-290a-3p, mmu-miR-467a-5p, hsamiR-3648, mmu-miR-465c-3p, mmu-mir-465b-3p, mmumiR-465a-3p, hsa-miR-6761-3p, mmu-miR-3086-5p, and hsa-miR-4313 (Table XI).

\section{Discussion}

Lung cancer is by far the leading cause of cancer-related deaths worldwide. The key lung cancer pathological types are small cell lung carcinoma $(\sim 15 \%)$ and non-small cell lung carcinoma (NSCLC) $(\sim 85 \%)$, with the later types comprising lung squamous cell carcinoma ( 40\%), lung adenocarcinoma $(\sim 40 \%)$ and lung large-cell carcinoma $(\sim 10 \%)$ (2). As NSCLC is a major type of lung cancer, the mechanism of treatment failure in this type of cancer is very interesting for researchers. The causes of drug resistance in lung cancer include cellular intrinsic mechanisms that drive the alterations of drug transporters, and the increase and activation of pro-survival and anti-apoptotic proteins (3-5, $27,28)$. In addition, recent studies have highlighted the vital roles of cancer environmental factors.

One important micro-environmental factor is nitric oxide (NO). NO is a relatively short-lived gas generated in the human body by the activity of nitric oxide synthase (NOS) enzymes and has been long known to act as a signaling molecule in the regulation of several physiological events (11). On the other hand, the abnormal as well as excessive production of NO can be implicated in many diseases including cancer (9). It was shown that near tumors, NO is highly produced by the immune cells (10). In addition, cancer cells themselves have a capability to produce NO at a high level. The expression of NOS has been reported in many cancers, including breast, cervical, head and neck, and lung cancer (29), and the presence of NO in the cancer area has been linked to the aggressiveness of the diseases (12). The expression of inducible nitric oxide synthase (iNOS) in cancer cells as well as the expression of NOS in the environment of cancers have been shown to predict poor survival (30). Molecular explanations on how NO regulates chemotherapeutic resistance as well as attenuates cancer cell 
Table III. The ENCODE TF ChIP-seq 2015 top ten enriched transcription factors affected by DPTA NONOate.

\begin{tabular}{|c|c|c|c|c|}
\hline Transcription factors & $p$-Value & OR & Combined score & Targeted genes from input genes \\
\hline CUX1_K562_hg19 & 0.002042 & 1.79 & 11.08 & $\begin{array}{c}\text { GFM1; INO8OD; NDUFB10; CEP164; FBXO48; } \\
\text { BAZ2B; FYCO1; DSCR4; ICT1; C3ORF75; } \\
\text { HMGXB3; YIPF } 2 ; \text { S100A1; CD3EAP; MRPS } ; \\
\text { FTSJD2; WBP11; TNFRSF1A; FBXL12; RPS26; } \\
\text { CENPE; IRAK1BP1; SAGE1;TAF7; SNRPE; } \\
\text { SDCCAG8; ZNF354B }\end{array}$ \\
\hline FOXM1_MCF-7_hg19 & 0.038685 & 3.15 & 10.26 & KCTD9; SERPINA3; PTTG1; UBE2S \\
\hline RFX5_K562_hg19 & 0.00415 & 1.72 & 9.44 & $\begin{array}{c}\text { GFM1; NDUFB10; CEP164; RPL11; KIAA1328; } \\
\text { PTTG1; GRPEL2; C3ORF75; SURF6; RPS2; } \\
\text { HMGXB3; SNAPIN; YIPF2; MRPS2; FTSJD2; } \\
\text { SENP2; FBXL12; RPS26; CENPE; MRPL51; } \\
\text { KLF5; MTHFD2; MRTO4; SNRPE; } \\
\text { MAN1B1; SDCCAG8 }\end{array}$ \\
\hline RAD21_IMR-90_hg19 & 0.00415 & 1.72 & 9.44 & $\begin{array}{c}\text { GFM1; C11ORF75; INO8OD; NDUFB10; HSPA4L; } \\
\text { RPL11; PDXP; EFNB1; ARL5B; KIAA1328; } \\
\text { ICT1; NRIP2; POLR2D; C3ORF75; ZNF362; } \\
\text { SNAPIN; FAM46A; MRPS2; FTSJD2; RPS26; } \\
\text { SFRP1; MRTO4; SNRPE; MAN1B1; IL17D; ZNF354B }\end{array}$ \\
\hline SMC3_K562_hg19 & 0.00415 & 1.72 & 9.44 & $\begin{array}{c}\text { GFM1; INO8OD; NDUFB10; HSPA4L; DDX41; } \\
\text { DSCR4; LAMP1; ICT1; GRPEL2; SNIP1; } \\
\text { NUDT18; C3ORF75; SURF6; RPS2; YIPF2; } \\
\text { CCDC59; MRPS2; FTSJD2; RPS26; SAGE1; MRTO4; } \\
\text { PRKCQ; SNRPE; PIK3C3; MAN1B1; POLR3K }\end{array}$ \\
\hline ELF1_K562_hg19 & 0.010994 & 1.80 & 8.13 & $\begin{array}{c}\text { GFM1; NDUFB10; HSPA4L; CEP164; MRPS2; } \\
\text { MYL6B; C12ORF45; RPS } 27 ; \text { MRPL51; PDP } 2 ; \\
\text { PTTG1; UBE2S; ORMDL2; SURF6; SNRPE; } \\
\text { RBAK; SDCCAG8; ZNF354B }\end{array}$ \\
\hline TAF1_GM12891_hg19 & 0.007749 & 1.66 & 8.07 & $\begin{array}{l}\text { SASH3; MYL6B; DDX41; FYCO1; PTTG1; } \\
\text { ORMDL2; GRPEL2; HSF1; NUDT18; C3ORF75; } \\
\text { SURF6; RPS2; HMGXB3; ICOSLG; SNAPIN; } \\
\text { MRPS2; FTSJD2; C12ORF45; STAG1; ERCC3; } \\
\text { MTHFD2; MRTO4; SNRPE; MAN1B1; RBAK }\end{array}$ \\
\hline ELK1_GM12878_hg19 & 0.008089 & 1.66 & 7.98 & $\begin{array}{c}\text { GFM1; INO8OD; NDUFB10; HSPA4L; } \\
\text { CEP164; RCBTB1; EFNB1; KIAA1328; } \\
\text { POLR2D; SNIP1; KNTC1; SNAPIN; } \\
\text { YIPF } 2 ; \text { FTSJD2; SENP2; TNFRSF1A; } \\
\text { RPS26; C12ORF45; ERCC3; SNRPE; } \\
\text { PIK3C3; MAN1B1; RBAK; POLR } 3 K ; \text { ZNF354B }\end{array}$ \\
\hline CREB1_GM12878_hg19 & 0.018309 & 1.99 & 7.95 & $\begin{array}{c}\text { RPS26; CENPE; RPS } 27 ; \text { SNIP1; NUDT18; } \\
\text { CHMP4B; PIK3C } 3 ; \text { RPS } 2 ; W B P 11 ; \\
\text { LONRF1; SENP } 2 ; \text { RBMS2 }\end{array}$ \\
\hline EBF1_GM12878_hg19 & 0.005999 & 1.54 & 7.88 & $\begin{array}{c}\text { SASH3; NDUFB10; RPL11; PDXP; MYL6B; } \\
\text { FYCO1; ARL5B; KIAA1328; LAMP1; GRPEL2; } \\
\text { KCNMB3; SNIP1; C3ORF75; RPS2; HMGXB3; } \\
\text { YIPF2; RHOG; MRPS2; FTSJD2; SENP2; FBXL12; } \\
\text { RPS26; KCTD9; IRAK1BP 1; STAG1; RPS27; } \\
\text { MRPL51; PDP 2; SNRPE; PIK3C3; } \\
\text { PLP } 2 ; \text { RBAK; POLR } 3 K ; \text { SDCCAG8 }\end{array}$ \\
\hline
\end{tabular}

OR: Odds ratio.

response to immune cell-mediated death have been suggested by many researchers $(11,31,32)$. NO was shown to control cancer cell response by directly interacting with the key proteins through S-nitrosylation which alter the stability and function of the target protein. S-nitrosylation at the cysteine of the Bcl-2 protein was demonstrated to be a possible cause of cisplatin resistance in NSCLC (19). Taken together, determination of the molecular mechanism underlying the controls of NO on lung cancer cells could lead to a better understanding and development of new therapeutic targets. 
Table IV. The transcription factor PPIs top ten enriched transcription factors affected by DPTA NONOate.

\begin{tabular}{lcccc}
\hline Transcription factors & $p$-Value & OR & Combined score & Targeted genes from input genes \\
\hline SIX5 & 0.04446 & 22.08 & 68.72 & ERCC3 \\
ILF2 & 0.00277 & 4.32 & 25.44 & RPS26; RCN1; LAMP1; ICT1; RPL11; RPS2 \\
MEF2A & 0.03174 & 7.16 & 24.70 & NFIX; PRKCQ \\
SMAD2 & 0.00261 & 3.10 & 18.47 & EPHB6; STAG1; SNAPIN; KLF5; \\
ZBTB7B & & & & ERCC3; S100A1; SNIP1; SURF6; SENP2 \\
NR2F2 & 0.12757 & 7.36 & 15.15 & GRAP2 \\
TBP & 0.15365 & 6.02 & 11.28 & FAM46A \\
ILF3 & 0.03324 & 3.31 & 11.27 & KLF5; HSF $;$ CD $3 E A P ;$ TAF7 \\
RARA & 0.02544 & 2.68 & 9.82 & RPS26; RCN1; LAMP1; RPL11; RPS2; PLP2 \\
USF2 & 0.04384 & 3.03 & 9.47 & KLF5; NRIP2; MRTO4; BAZ2B \\
\hline
\end{tabular}

OR: Odds ratio.

Table V. The TRANSFAC and JASPAR PWMs top ten enriched transcription factors affected by DPTA NONOate.

\begin{tabular}{|c|c|c|c|c|}
\hline Transcription factors & $p$-Value & OR & Combined score & Targeted genes from input genes \\
\hline ESR2 (mouse) & 0.056767 & 5.19 & 14.90 & NUDT18; PIK3C3 \\
\hline RARA (human) & 0.003698 & 1.92 & 10.76 & $\begin{array}{l}\text { YIPF2; HSPA4L; CEP164; MYL6B; FTSJD2; } \\
\text { JOSD1; GCSH; RPS26; SFRP1; RCN1; } \\
\text { RPS27; KIAA1328; HSF1; SURF6; HMG2OB; } \\
\quad \text { SNRPE; RLN1; MAN1B1; PLP2; RBMS2 }\end{array}$ \\
\hline JDP2 (human) & 0.004029 & 1.87 & 10.31 & $\begin{array}{l}\text { LGI4; FTSJD2; BAZ2B; WBP11; GUCY2F; } \\
\text { CENPE; ARGFX; STAG1; RFPL4B; MRPL51; } \\
\text { PLN; PDP2; ICT1; ASB9; PRKCQ; SNRPE; } \\
\text { RLN1; RPS2; CMTM2; POLR3K; RBMY1B }\end{array}$ \\
\hline NR1H2 (human) & 0.029206 & 2.21 & 7.82 & $\begin{array}{l}\text { KIAA1328; YIPF } 2 ; \text { RPL } 11 ; \text { HSF } 1 ; \\
\text { HMG2OB; SNRPE; MYL6B; RLN1 }\end{array}$ \\
\hline FOXA1 (human) & 0.026529 & 1.64 & 5.94 & $\begin{array}{c}\text { G6PC; RPL11; PDXP; KLHL34; KCTD3; SENP2; } \\
\text { INHBC; RPS26; RPS27; GRPEL2; CLDN23; } \\
\text { KCNMB3; ZNF514; SNRPE; HPRT1; } \\
\text { POLR3K; RAB4OAL; SDCCAG8 }\end{array}$ \\
\hline SND1 (mouse) & 0.148033 & 2.94 & 5.62 & TRHDE; TNFRSF1A \\
\hline FOXO3A (human) & 0.044372 & 1.79 & 5.58 & $\begin{array}{c}\text { FAM167B; IRAK1BP1; G6PC; } \\
\text { NFIX; CLDN23; RPL11; KCNMB3; } \\
\text { KLHL34; SNRPE; POLR3K; SDCCAG8 }\end{array}$ \\
\hline Myb (mouse) & 0.028672 & 1.53 & 5.44 & $\begin{array}{c}\text { CDS1; S100A1; CEP164; DDX41; ARHGAP15; } \\
\text { SENP2; TNFRSF1A; DCBLD2; GCSH; } \\
\text { KCTD9; FAM167B; RFPL4B; RPS27; } \\
\text { MRPL51; MYH3; ORMDL2; VWC2; SNIP1; } \\
\text { NUDT18; MAN1B1; POLR3K; SDCCAG8 }\end{array}$ \\
\hline IRF1 (human) & 0.2561 & 3.40 & 4.63 & $R F P L 4 B$ \\
\hline ELK1 (human) & 0.063785 & 1.49 & 4.10 & $\begin{array}{c}\text { C11ORF75; INO80D; LGI4; CEP164; CD3EAP; } \\
\text { MYL6B; RPS26; FLJ32063; RPS27; MRPL51; } \\
\text { KLF5; SAGE1; GRAP2; CCDC88C; TAF7; } \\
\text { RLN1; RBMY1B }\end{array}$ \\
\hline
\end{tabular}

OR: Odds ratio.

Focusing on novel molecular-based insights, it has become widely accepted that tumors are composed of heterogeneous cells with a variety of characteristics that make the cells respond differently to treatment (33). Besides, after chemotherapeutic management, lung cancer often develops resistant clones. It is now accepted that cancer heterogeneity is mainly governed by a small special subpopulation of cancer cells with high self-renewal capacity, termed cancer stem cells (CSCs). CSCs have the ability to initiate tumor through their self-renewing and multi-lineage differentiation 
Table VI. The Enrichr Submission TF-Gene co-occurrence top ten of enriched transcription factors affected by DPTA NONOate.

\begin{tabular}{|c|c|c|c|c|}
\hline Transcription factors & $p$-Value & OR & Combined score & Targeted genes from input genes \\
\hline ZNF593 & 0.00046 & 3.99 & 30.65 & $\begin{array}{l}\text { RPS26; PTTG1; NDUFB10; MTHFD2; } \\
\text { UBE2S; MRTO4; RPL11; CD3EAP; RPS2 }\end{array}$ \\
\hline CPSF4 & 0.00200 & 3.54 & 22.03 & $\begin{array}{c}\text { CENPE; MTHFD } 2 ; \text { MRTO4; POLR2D; } \\
\text { CD3EAP; HMG2OB; MRPS } 2 ; \text { RPS2 }\end{array}$ \\
\hline ZNF511 & 0.00200 & 3.54 & 22.03 & $\begin{array}{l}\text { PTTG1; NDUFB10; MTHFD2; UBE2S; } \\
\text { MRTO4; CD } 3 E A P ; R P S 2 ; \text { POLR } 3 K\end{array}$ \\
\hline BOLA3 & 0.00772 & 3.10 & 15.08 & $\begin{array}{c}\text { RPS26; MRPL51; PTTG1; NDUFB10; } \\
\text { MTHFD2; CD3EAP; RPS } 2\end{array}$ \\
\hline HMGB3 & 0.00772 & 3.10 & 15.08 & $\begin{array}{c}\text { CENPE; PTTG1; MTHFD2; UBE2S; } \\
\text { CD } 3 E A P ; K N T C 1 ; H P R T 1\end{array}$ \\
\hline PRMT3 & 0.00772 & 3.10 & 15.08 & $\begin{array}{c}\text { PTTG1; MTHFD2; MRTO4; POLR2D; } \\
\text { CD3EAP; KNTC1; HPRT1 }\end{array}$ \\
\hline THAP11 & 0.00772 & 3.10 & 15.08 & $\begin{array}{c}\text { NDUFB10; MTHFD } 2 ; R P L 11 ; \text { POLR2D; } \\
\text { CD } 3 E A P ; M R P S 2 ; R P S 2\end{array}$ \\
\hline YEATS4 & 0.00772 & 3.10 & 15.08 & $\begin{array}{c}\text { CENPE; PTTG1; MTHFD2; CD3EAP; } \\
\text { KNTC1; SNRPE; HPRT1 }\end{array}$ \\
\hline ZMAT2 & 0.00772 & 3.10 & 15.08 & $\begin{array}{c}\text { RPS26; NDUFB10; RPL11; CD3EAP; } \\
\text { CHMP4B; SNRPE; RPS2 }\end{array}$ \\
\hline ZNF121 & 0.00772 & 3.10 & 15.08 & $\begin{array}{c}\text { CENPE; ARL5B; MTHFD } 2 ; \text { GRPEL2 } \\
\text { POLR } 2 D ; C D 3 E A P ; K N T C 1\end{array}$ \\
\hline
\end{tabular}

OR: Odds ratio.

Table VII. The ENCODE and ChEA consensus TFs from ChiP-X top ten enriched transcription factors affected by DPTA NONOate.

\begin{tabular}{|c|c|c|c|c|}
\hline Transcription factors & $p$-Value & OR & Combined score & Targeted genes from input genes \\
\hline CBX3_ENCODE & 0.023455 & 4.91 & 18.41 & GFM1; LAMP1; CCDC59 \\
\hline FOXM1_ENCODE & 0.035281 & 4.18 & 13.99 & KCTD9; PTTG1; UBE2S \\
\hline ATF2_ENCODE & 0.00736 & 1.53 & 7.53 & $\begin{array}{l}\text { INOSOD; NDUFB10; RPL11; FBXO48; BAZ2B; } \\
\text { LAMP1; ICT1; ORMDL2; GRPEL2; SNIP1; } \\
\text { NUDT18; SURF6; KNTC1; RPS2; HMGXB3; } \\
\text { PSTK; YIPF2; CCDC59; CD3EAP; JOSD1; } \\
\text { SENP2; RPS26; CENPE; IRAK1BP1; STAG1; } \\
\text { RPS27; MRPL51; MTHFD2; UBE2S; } \\
\text { CCDC88C; TAF7; SNRPE; RBMS2 }\end{array}$ \\
\hline SALL4_CHEA & 0.05283 & 2.24 & 6.58 & STAG1; RCN1; PLN; KLF5; CASQ2; PRKCQ \\
\hline MAX_ENCODE & 0.022343 & 1.53 & 5.83 & $\begin{array}{c}\text { GFM1; RPL11; RHOG; CD3EAP; MRPS2; } \\
\text { PDXP; DDX41; SENP2; RCBTB1; GCSH; } \\
\text { MRPL51; PER3; KLF5; LAMP1; MTHFD2; } \\
\text { UBE2S; MRTO4; CCDC88C; HSF1; } \\
\text { SURF6; SNRPE; MAN1B1; RPS2; POLR3K }\end{array}$ \\
\hline KAT2A_ENCODE & 0.148033 & 2.94 & 5.62 & RPL11; RPS2 \\
\hline IRF3_ENCODE & 0.064431 & 1.80 & 4.93 & $\begin{array}{c}\text { KCTD } 9 ; P D P 2 ; K L F 5 ; M T H F D 2 ; \\
\text { ORMDL2; CEP164; PDXP; KNTC1;WBP11 }\end{array}$ \\
\hline POU5F1_CHEA & 0.135689 & 2.03 & 4.05 & KCTD9; SFRP1; STAG1; GRAP2 \\
\hline NR2C2_ENCODE & 0.126159 & 1.89 & 3.92 & RPS26; GFM1; CCDC59; CHMP4B; SURF6 \\
\hline PPARG_CHEA & 0.11117 & 1.73 & 3.81 & $\begin{array}{c}\text { GALNT6; STAG1; NDUFB10; GPD1; } \\
\text { RBAK; SENP2; SDCCAG8 }\end{array}$ \\
\hline
\end{tabular}

OR: Odds ratio.

$(34,35)$. Regarding lung cancer, many studies have reported the presence of CSCs in NSCLC and associated them to drug resistance, metastasis, and cancer relapse (36). Moreover, several pieces of evidences have shown that NO can promote the aggressive behavior of cancer for which CSCs are responsible $(7,17,18,20,21,25)$.

Herein, we focused on illustrating the molecular profile of the NSCLC exposed to a non-toxic concentration of NO that 
Table VIII. The ARCHS4 TFs top ten enriched transcription factors affected by DPTA NONOate.

\begin{tabular}{|c|c|c|c|c|}
\hline Transcription factors & $p$-Value & OR & $\begin{array}{l}\text { Combined } \\
\text { score }\end{array}$ & $\begin{array}{l}\text { Targeted genes from } \\
\text { input genes }\end{array}$ \\
\hline KLF15_human_tf_ARCHS4_coexpression & 0.001997 & 3.54 & 22.03 & $\begin{array}{l}\text { FYCO1; G6PC; NFIX; S100A1; } \\
\text { GPD1;IL17D; INHBC; UGT2B7 }\end{array}$ \\
\hline ZNF528_human_tf_ARCHS4_coexpression & 0.001997 & 3.54 & 22.03 & $\begin{array}{l}\text { C12ORF45; MAS1; KIAA1328; PIK3C3; } \\
\text { GPR4; BAZ2B; HTN1; SDCCAG8 }\end{array}$ \\
\hline MYF6_human_tf_ARCHS4_coexpression & 0.007723 & 3.10 & 15.08 & $\begin{array}{c}\text { FYCO1; PLN; S100A1; CASQ2; } \\
\text { KLHL34; PRKCQ;IL17D }\end{array}$ \\
\hline ZBED1_human_tf_ARCHS4_coexpression & 0.007723 & 3.10 & 15.08 & $\begin{array}{l}\text { SASH3; FYCO1; LAMP1; HSF } 1 \\
\text { CHMP4B; HMG2OB; TNFRSF1A }\end{array}$ \\
\hline PRDM15_human_tf_ARCHS4_coexpression & 0.007723 & 3.10 & 15.08 & $\begin{array}{c}\text { C12ORF } 45 ; \text { KIAA1328; PDP } 2 ; \\
\text { CCDC88C; BRI3BP; ICOSLG; HTN1 }\end{array}$ \\
\hline GPR155_human_tf_ARCHS4_coexpression & 0.007723 & 3.10 & 15.08 & $\begin{array}{l}\text { C12ORF45; MAS1; KIAA1328; } \\
\text { FBXO48; PIK3C3; BAZ2B; HTN1 }\end{array}$ \\
\hline SOX10_human_tf_ARCHS4_coexpression & 0.026176 & 2.66 & 9.68 & FAM167B; NFIX; S100A1; LGI4; AATK; HMG20B \\
\hline POU6F2_human_tf_ARCHS4_coexpression & 0.026176 & 2.66 & 9.68 & C12ORF45; MAS1; KIAA1328; VWC2; BAZ2B; HTN1 \\
\hline ELK3_human_tf_ARCHS4_coexpression & 0.026176 & 2.66 & 9.68 & KCTD9; GRAP2; PPBP; PLP2; RBMS2; TNFRSF1A \\
\hline NPAS1_human_tf_ARCHS4_coexpression & 0.026176 & 2.66 & 9.68 & NDUFB10; UBE2S; MRPS2; PDXP; RPS2;IL17D \\
\hline
\end{tabular}

OR: Odds ratio.

may mimic the phenomenon in lung cancer environments. The mRNAs of NO-treated cells were analyzed with microarrays and bioinformatics approaches to identify potential transcription factors and epigenetics modifiers in comparison to those of un-treated cells. Our results showed that several transcription factors identified as molecular targets of NO play a role in the formation and maintenance of CSC (20) and the aggressive behaviors related with CSCs $(17,18,25)$. These results, along with cell-based analysis, revealed that NO promotes the dedifferentiation of lung cancer by increasing the CSC transcription factors and proteins (21).

Since induced pluripotent stem cells (iPS) are originally generated from murine fibroblasts, which involve transfection by four transcription factors (yamanaka factors); namely Sox2, Oct3/4, c-Myc, and Klf4 (37), these transcription factors have been extensively examined for their role in CSCs (38). Our results predicted that the four Yamanaka factors (Oct4, Sox2, $\mathrm{Myc}$, and Klf4) were potential transcription factors affected by NO. Octamer binding transcription (Oct) is a subclass of the POU transcription factor family proteins, which bind a specific eight-base-pair on DNA sequence [ATGC(A/T)AAT] (octamer motif) and control the transcriptional processes of certain genes. Oct 4 acts as a core protein to facilitate the other stemness related proteins, Sox2, and nanog, to form a transcription factor complex and promote the transcriptional process of stemness genes $(39,40)$. There is strong evidence indicating Oct4 has a CSC formation capacity and its malignancy phenotype has an enhancing effect (41-44). SYRrelated HMG-box (Sox) is a transcription factor binding to ATTGTT or a related sequence on the HMG domain and it regulates both the differentiation and dedifferentiation process

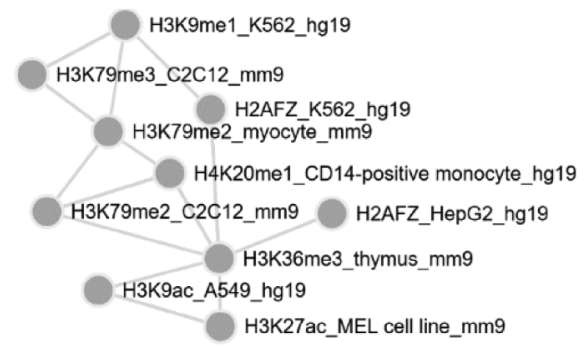

Figure 3. Potential epigenetics network. Histone modification network from ENCODE histone modifications 2015.

of cells. The function of the Sox protein on differentiation processes of the cell depends on its transcription protein partner (45-47). Sox2 has been observed to have dedifferentiation activity both in normal and cancer cells. A high protein expression of Sox 2 and Oct4 is related to poor prognosis and aggressiveness of the disease $(48,49)$. MYC is a protein family of a group of basic-helix-loop-leucine zipper transcription factors that regulate cell proliferation, growth, metabolism, cell-cycle progression, and differentiation. This family consists with three forms, c-Myc, N-Myc, and L-Myc, which have been attracting growing interest for their function in stem cell regulation. In addition, evidence has established an emerging role of Myc in CSC regulation (50-53). Kruppellike factor4, Klf4, is a protein member of the zinc fingercontaining transcription factor family that regulates numerous cellular biological processes, such as cell differentiation, growth and proliferation, and apoptosis (54). In cancer, Klf4 has exhibited a role as a dual-function transcription factor, 
Table IX. The ENCODE histone modifications 2015 top ten enriched transcription factors affected by DPTA NONOate.

\begin{tabular}{|c|c|c|c|c|}
\hline Histone modification & $p$-Value & OR & Combined score & Targeted genes from input genes \\
\hline H3K79me3_C2C12_mm9 & 0.008089 & 1.66 & 7.98 & $\begin{array}{c}\text { GFM1; HSPA4L; RPL11; DDX41; GCSH; GRPEL2; } \\
\text { HSF1; SNIP1; KNTC1; RPS2; CD3EAP; MRPS2; FTSJD2; } \\
\text { KCTD3; WBP11; TNFRSF1A; FBXL12; MRPL51; } \\
\text { UBE2S; MRTO4; TAF7; SNRPE; MAN1B1; PLP2; POLR3K }\end{array}$ \\
\hline H3K9me1_K562_hg19 & 0.026988 & 1.52 & 5.50 & $\begin{array}{l}\text { EPHB6; ZNF782; GALNT6; LGI4; PLAC1L; GPR4; } \\
\text { FTSJD2; SENP2; INHBC; FAM167B; DSCR4; ARL5B; } \\
\text { PDP2; PTTG1; ICT1; GPD1; GRPEL2; CLDN23; } \\
\text { HMG2OB; SNRPE; PIK3C3; HMGXB3; IL17D }\end{array}$ \\
\hline H3K79me2_C2C12_mm9 & 0.046138 & 1.46 & 4.48 & $\begin{array}{c}\text { GFM1; RPL11; MRPS2; DDX41; WBP } 11 ; \text { FBXL12; } \\
\text { RPS26; MRPL51; PDP2;PTTG1; ERCC3; UBE2S; ICT1; } \\
\text { MRTO4; HSF1; SNIP1; KNTC1; SNRPE; } \\
\text { MAN1B1; RPS2; PLP2; POLR3K }\end{array}$ \\
\hline H2AFZ_HepG2_hg19 & 0.046138 & 1.46 & 4.48 & $\begin{array}{c}\text { G6PC; INO8OD; SNAPIN; MYL6B; DDX41; FBXL12; } \\
\text { RPS26; EFNB1; C12ORF45; MRPL51; KIAA1328; PDP2; } \\
\text { UBE2S; MRTO4; POLR2D; C3ORF75; SURF6; TAF7; } \\
\text { PIK3C3; HMGXB3; POLR3K; UGT2B7 }\end{array}$ \\
\hline H3K36me3_thymus_mm9 & 0.083828 & 1.50 & 3.72 & $\begin{array}{c}\text { SASH3; NDUFB10; RPL11; MRPS2; PDXP; } \\
\text { THY1; FBXL12; RPS26; RPS27; UBE2S; } \\
\text { GRAP2; ORMDL2; SNRPE; RPS2 }\end{array}$ \\
\hline H3K27ac_MEL cell line_mm9 & 0.075402 & 1.39 & 3.59 & $\begin{array}{l}\text { GFM1; SNAPIN; NDUFB10; HSPA4L; FBXO48; } \\
\text { MRPS2; MYL6B; BAZ2B; ARHGAP15; RPS26; } \\
\text { FYCO1; RPS27; PDP2; ICT1; POLR2D; HSF1; } \\
\text { SNIP1; TAF7; KNTC1; SNRPE; PSTK }\end{array}$ \\
\hline $\begin{array}{l}\text { H4K20me1_CD14- } \\
\text { positive monocyte_hg19 }\end{array}$ & 0.075402 & 1.39 & 3.59 & $\begin{array}{l}\text { ZNF782; SNAPIN; NFIX; NDUFB10; YIPF2; } \\
\text { CD3EAP; MRPS2; PDXP; DDX41; OSD1; BRI3BP; } \\
\text { KCTD9; EFNB1; ICT1; NRIP2; POLR2D; SNIP1; } \\
\text { SURF6; HMG2OB; RPS2; POLR3K }\end{array}$ \\
\hline H3K9ac_A549_hg19 & 0.075402 & 1.39 & 3.59 & $\begin{array}{l}\text { ZNF782; PRRT1; MRPS2; MYL6B; DDX41; WBP11; } \\
\text { SENP2; CELSR2; RCBTB1; ARL5B; KIAA1328; } \\
\text { PER3; CCDC } 88 C ; H S F 1 ; H M G 20 B ; Z N F 514 ; \text { TAF7; } \\
\text { POLR } 3 K ; \text { ICOSLG; UGT2B7; ZNF354B }\end{array}$ \\
\hline H3K79me2_myocyte_mm9 & 0.075402 & 1.39 & 3.59 & $\begin{array}{c}\text { GFM1; HSPA4L; RPL11; MRPS2; TNFRSF1A; } \\
\text { FBXL12; RPS26; ARL5B; MRPL51;PDP2;ERCC3; } \\
\text { UBE2S; MRTO4;HSF1; SNIP1;TAF7; } \\
\text { KNTC1; SNRPE;PIK3C3; RPS2;POLR } 3 K\end{array}$ \\
\hline H3K36me3_Caco-2_hg19 & 0.163209 & 1.73 & 3.14 & RPS26; RPS27; UBE2S; TAF7; RPS2 \\
\hline
\end{tabular}

OR: Odds ratio.

whereby it acts as an onco-protein or a tumor suppressor protein depending on the type of cancer and stage of the disease (55). There is less clear information available on the function of Klf4 in CSCs regulation compared to the other three transcription factors. Since Klf4 showed a function as an onco-protein, it is believed to involve in the proliferation of CSCs (54).

According to the emerging role of epigenetics in the regulation of gene expression, several epigenetic modifiers have been extensively studied regarding their activity on CSC formation and maintenance (56). Histone and DNA modification control gene transcription by regulating the structure of chromatin and DNA, which allows or does not allow transcription factors to interact and promote the expression of their target gene $(57,58)$. miRNAs control gene expression by regulating the levels of its target miRNAs, which regulate the self-renewal and differentiation of cancer stem cells (59). Herein, we found several potential histone modifications and miRNAs that could be the targets of NO. H3K36me3 was shown to have the highest degree of epigenetic modification hubs that were altered by NO exposure. H3K36me3 was also found to be associated with a poor prognosis in hepatocellular carcinoma (60) and corelated with cancer-related gene expression in cancer cell lines (61). In addition, $\mathrm{H} 3 \mathrm{~K} 79 \mathrm{Me} 3$ is one of the histone modifications of interest due to controlling epithelial-to-mesenchymal (EMT) (62) and the stemness of certain cells (63). H3K9Me1 has exhibited capacity for liver cancer formation (64) and was found to be a prognosis marker in oral cancer and oropharyngeal squamous cell carcinoma (65).

Furthermore, the suggested miRNAs from bioinformatic analyses have been documented for their cancer-related 
Table X. The TargetScan microRNA2017 top ten enriched transcription factors affected by DPTA NONOate.

\begin{tabular}{|c|c|c|c|c|}
\hline miRNAs & $p$-Value & OR & Combined score & Targeted genes from input genes \\
\hline hsa-miR-4749-5p & 0.009069 & 1.88 & 8.84 & $\begin{array}{c}\text { PRRT1; NFIX; AATK; PDXP; MYL6B; THY1; } \\
\text { FAM167B; SFRP1; RCN1; GPD1; CLDN23; HSF1, } \\
\text { SURF6; HMG2OB; MAN1B1; ICOSLG; SDCCAG8 }\end{array}$ \\
\hline hsa-miR-4706 & 0.009069 & 1.88 & 8.84 & $\begin{array}{c}\text { PRRT1; NFIX; AATK; PDXP; MYL6B; THY1; } \\
\text { FAM167B; SFRP1; RCN1; GPD1; CLDN23; } \\
\text { HSF1; SURF6; HMG2OB; MAN1B1; } \\
\text { ICOSLG; SDCCAG8 }\end{array}$ \\
\hline hsa-miR-615-3p & 0.019615 & 2.24 & 8.83 & $\begin{array}{c}\text { PRRT1; GALNT6; ZNF362; NFIX; POLR2D; } \\
\text { HSF1; JOSD1; IL17D; CELSR2 }\end{array}$ \\
\hline mmu-miR-3072 & 0.019402 & 1.64 & 6.46 & $\begin{array}{c}\text { PRRT1; COLEC12; ZNF362; INO8OD; LGI4; } \\
\text { HSPA4L; CD3EAP; PDXP; MYL6B; JOSD1; } \\
\text { CELSR2; RCBTB1; UBE2S; GRAP2; ORMDL2; } \\
\text { KCNMB3; CASQ2; NUDT18; LONRF1; ICOSLG }\end{array}$ \\
\hline hsa-miR-28-3p & 0.024211 & 1.60 & 5.96 & $\begin{array}{l}\text { G6PC; INO8OD; NFIX; FAM46A; FBXO48; } \\
\text { JOSD1; SENP2; CELSR2; RCBTB1; DCBLD2; } \\
\text { ARGFX; ARLSB; PLN; GRPEL2; POLR } 2 D ; \\
\text { ASB9; CASQ2; PRKCQ; LONRF1; RBMS2 }\end{array}$ \\
\hline mmu-miR-187 & 0.055948 & 1.94 & 5.59 & $\begin{array}{c}\text { KCTD9; INO8OD; SNAPIN; PLN; PER3; } \\
\text { FAM46A; LONRF1; RBAK }\end{array}$ \\
\hline mmu-miR-695 & 0.035791 & 1.67 & 5.55 & $\begin{array}{c}\text { PRRT1; COLEC12; ZNF362; NFIX; LGI4; } \\
\text { FAM46A; PDXP; JOSD1; CELSR2; TRHDE; } \\
\text { EFNB1; ASB } ; \text { PRKCQ; PLP2; RBMS } 2\end{array}$ \\
\hline hsa-miR-4781-5p & 0.04838 & 1.77 & 5.35 & $\begin{array}{l}\text { PRRT1; NFIX; LGI4; CEP164; POLR2D; HSF1; } \\
\quad \text { SURF6; THY1; CELSR2; INHBC; ICOSLG }\end{array}$ \\
\hline hsa-miR-572 & 0.074612 & 1.92 & 4.97 & $\begin{array}{c}\text { RCN1; INO8OD; NFIX; POLR2D; } \\
\text { MRPS2; TAF7; BRI3BP }\end{array}$ \\
\hline mmu-miR-1947 & 0.081796 & 1.87 & 4.69 & $\begin{array}{l}\text { KCTD9; EFNB1; INO8OD; PER3; } \\
\quad \text { GRAP } 2 ; \text { POLR } 2 D ; R B M S 2\end{array}$ \\
\hline
\end{tabular}

OR: Odds ratio.

Table XI. The miTarBase2017 top ten enriched transcription factors affected by DPTA NONOate.

\begin{tabular}{lcccc}
\hline miRNAs & $p$-Value & OR & Combined score & Targeted genes from input genes \\
\hline mmu-miR-292a-3p & 0.002449 & 26.49 & 159.26 & PDP2; MYL6B \\
mmu-miR-290a-3p & 0.002978 & 24.08 & 140.07 & PDP2; MYL6B \\
mmu-miR-467a-5p & 0.002978 & 24.08 & 140.07 & PDP2; MYL6B \\
hsa-miR-3648 & 0.009841 & 13.25 & 61.21 & NFIX; YIPF2 \\
mmu-miR-465c-3p & 0.051675 & 18.92 & 56.06 & DCBLD2 \\
mmu-miR-465b-3p & 0.051675 & 18.92 & 56.06 & DCBLD2 \\
mmu-miR-465a-3p & 0.051675 & 18.92 & 56.06 & NFIX \\
hsa-miR-6761-3p & 0.051675 & 18.92 & 56.06 & BRI3BP \\
mmu-miR-3086-5p & 0.051675 & 18.92 & 56.06 & PER3; UBE2S; GRAP2; FBXO48 \\
hsa-miR-4313 & 0.001655 & 7.91 & 50.64 &
\end{tabular}

OR: Odds ratio.

activities. miR-615-3p has been found to be target of Nanog/OCT4/TCF3 protein (66) and showed an association with cancer recurrence in hepatocellular carcinoma (67). miR-3648 has been identified to play a role in the regulation of both the proliferation $(68,69)$ and invasion $(70)$ of certain cancers.
Transcription factors, histone modifications, and miRNAs have been shown to have roles in CSCs and CSC-related behaviors. Although certain molecular targets of $\mathrm{NO}$ for controlling tumor aggressiveness and the CSC phenotype have been elucidated, the analysis by whole mRNA expression with validated bioinformatics tools has not been 
elucidated. Herein, we provide valuable data that demonstrate potential new targets of $\mathrm{NO}$ in regulating cancer progression that can benefit NO research and offer knowledge on cancer cell biology.

\section{Conflicts of Interest}

The Authors declare that they have no competing interests.

\section{Authors' Contributions}

Supervision: P.C.; Participated in research design: A.M. and P.C.; Conducted experiments: A.M.; Performed data analysis: A.M. and O.P.; Wrote or contributed to the writing of the manuscript: A.M. and P.C.

\section{Acknowledgements}

The present work was supported by Grant RSA6180036 from the Thailand Research Fund.

\section{Availability of Data and Material}

The datasets used during the present study are available from the corresponding author upon reasonable request.

\section{References}

1 Siegel RL, Miller KD and Jemal A: Cancer statistics, 2018. CA Cancer J Clin 68(1): 7-30, 2018. PMID: 29313949. DOI: $10.3322 /$ caac. 21442

2 Torre LA, Siegel RL and Jemal A: Lung cancer statistics. Adv Exp Med Biol 893: 1-19, 2016. PMID: 26667336. DOI: 10.1007/978-3-319-24223-1_1

3 Massion PP and Carbone DP: The molecular basis of lung cancer: Molecular abnormalities and therapeutic implications. Respiratory research 4(1): 12-12, 2003. PMID: 14641911. DOI: 10.1186/1465-9921-4-12

4 Esposito L, Conti D, Ailavajhala R, Khalil N and Giordano A: Lung cancer: Are we up to the challenge?. Curr Genomics 11(7): 513518, 2010. PMID: 21532835. DOI: 10.2174/138920210793175903

5 Dela Cruz CS, Tanoue LT and Matthay RA: Lung cancer: Epidemiology, etiology, and prevention. Clin chest med 32(4): 605644, 2011. PMID: 22054876. DOI: 10.1016/j.ccm.2011.09.001

6 Quail DF and Joyce JA: Microenvironmental regulation of tumor progression and metastasis. Nat med 19(11): 1423-1437, 2013. PMID: 24202395. DOI: 10.1038/nm.3394

7 Luanpitpong $\mathrm{S}$ and Chanvorachote P: Nitric oxide and aggressive behavior of lung cancer cells. Anticancer Res 35(9): 4585-4592, 2015. PMID: 26254346.

8 Masri F: Role of nitric oxide and its metabolites as potential markers in lung cancer. Ann Thorac Med 5(3): 123-127, 2010. PMID: 20835304. DOI: 10.4103/1817-1737.65036

9 Fukumura D, Kashiwagi S and Jain RK: The role of nitric oxide in tumour progression. Nat Rev Cancer 6(7): 521-534, 2006. PMID: 16794635. DOI: $10.1038 / \mathrm{nrc} 1910$

10 Luiking YC, Engelen MPKJ and Deutz NEP: Regulation of nitric oxide production in health and disease. Curr Opin Clin
Nutr 13(1): 97-104, 2010. PMID: 19841582. DOI: 10.1097/ MCO.0b013e328332f99d

11 Hirst DG and Robson T: Nitric oxide physiology and pathology. Methods Mol Biol 704: 1-13, 2011. PMID: 21161625. DOI: 10.1007/978-1-61737-964-1_1

12 Liu PF, Zhao DH, Qi Y, Wang JG, Zhao M, Xiao K and Xie LX: The clinical value of exhaled nitric oxide in patients with lung cancer. Clin Respir J, 2016. PMID: 26934059. DOI: 10.1111/crj.12471

13 Vannini F, Kashfi K and Nath N: The dual role of inos in cancer. Redox Biol 6: 334-343, 2015. PMID: 26335399. DOI: 10.1016/j.redox.2015.08.009

14 Burke AJ, Sullivan FJ, Giles FJ and Glynn SA: The yin and yang of nitric oxide in cancer progression. Carcinogenesis 34(3): 503-512, 2013. PMID: 23354310. DOI: 10.1093/carcin/bgt034

15 Wang X, Zalcenstein A and Oren M: Nitric oxide promotes p53 nuclear retention and sensitizes neuroblastoma cells to apoptosis by ionizing radiation. Cell Death Differ 10(4): 468-476, 2003. PMID: 12719724. DOI: 10.1038/sj.cdd.4401181

16 Olson SY and Garbán HJ: Regulation of apoptosis-related genes by nitric oxide in cancer. Nitric Oxide-Biol Ch 19(2): 170-176, 2008. PMID: 18460349. DOI: 10.1016/j.niox.2008.04.005

17 Saisongkorh V, Maiuthed A and Chanvorachote P: Nitric oxide increases the migratory activity of non-small cell lung cancer cells via akt-mediated integrin alphav and beta1 upregulation. Cell Oncol (Dordr) 39(5): 449-462, 2016. PMID: 27376838. DOI: $10.1007 / \mathrm{s} 13402-016-0287-3$

18 Powan P and Chanvorachote P: Nitric oxide mediates cell aggregation and mesenchymal to epithelial transition in anoikisresistant lung cancer cells. Mol Cell Biochem 393(1-2): 237-245, 2014. PMID: 24771070. DOI: 10.1007/s11010-014-2066-7

19 Chanvorachote P, Nimmannit U, Stehlik C, Wang L, Jiang BH, Ongpipatanakul B and Rojanasakul Y: Nitric oxide regulates cell sensitivity to cisplatin-induced apoptosis through s-nitrosylation and inhibition of bcl-2 ubiquitination. Cancer Res 66(12): 6353-6360, 2006. PMID: 16778213. DOI: 10.1158/0008-5472.CAN-05-4533

20 Yongsanguanchai N, Pongrakhananon V, Mutirangura A, Rojanasakul Y and Chanvorachote P: Nitric oxide induces cancer stem cell-like phenotypes in human lung cancer cells. Am J Physiol Cell Physiol 308(2): C89-100, 2015. PMID: 25411331. DOI: 10.1152/ajpcell.00187.2014

21 Maiuthed A, Bhummaphan N, Luanpitpong S, Mutirangura A, Aporntewan C, Meeprasert A, Rungrotmongkol T, Rojanasakul $\mathrm{Y}$ and Chanvorachote P: Nitric oxide promotes cancer cell dedifferentiation by disrupting an oct4: Caveolin-1 complex: A new regulatory mechanism for cancer stem cell formation. J Biol Chem 293(35): 13534-13552, 2018. PMID: 29986880. DOI: 10.1074/jbc.RA117.000287

22 Diniz WJ and Canduri F: Review-article bioinformatics: An overview and its applications. Genet Mol Res 16(1): 2017. PMID: 28301675. DOI: 10.4238/gmr 16019645

23 Loewe RP and Nelson PJ: Microarray bioinformatics. Methods Mol Biol 671: 295-320, 2011. PMID: 20967638. DOI: 10.1007/978-1-59745-551-0_18

24 Roumpeka DD, Wallace RJ, Escalettes F, Fotheringham I and Watson M: A review of bioinformatics tools for bio-prospecting from metagenomic sequence data. Front Genet 8(23), 2017. PMID: 28321234. DOI: 10.3389/fgene.2017.00023

25 Chanvorachote P, Pongrakhananon V and Chunhacha P: Prolonged nitric oxide exposure enhances anoikis resistance and 
migration through epithelial-mesenchymal transition and caveolin-1 upregulation. BioMed Res Int: 941359, 2014. PMID: 24967418. DOI: $10.1155 / 2014 / 941359$

26 Aporntewan C and Mutirangura A: Connection up- and downregulation expression analysis of microarray (CU-DREAM): a physiogenomic discovery tool. Asian Biomed 5(2): 257-262, 2011. DOI: $10.5372 / 1905-7415.0502 .034$

27 Shanker M, Willcutts D, Roth JA and Ramesh R: Drug resistance in lung cancer. Lung Cancer 1: 23-36, 2010. PMID: 28210104.

28 Tsvetkova E and Goss GD: Drug resistance and its significance for treatment decisions in non-small-cell lung cancer. Curr Oncol 19(Suppl 1): S45-51, 2012. PMID: 22787410. DOI: 10.3747/ co. 19.1113

29 Choudhari SK, Chaudhary M, Bagde S, Gadbail AR and Joshi V: Nitric oxide and cancer: A review. World J Surg Oncol 11: 118, 2013. PMID: 23718886. DOI: 10.1186/1477-7819-11-118

30 Liao W, Ye T and Liu H: Prognostic value of inducible nitric oxide synthase (inos) in human cancer: A systematic review and meta-analysis. Biomed Res Int 2019: 6304851, 2019. PMID: 31275981. DOI: $10.1155 / 2019 / 6304851$

31 Banick PD, Chen Q, Xu YA and Thom SR: Nitric oxide inhibits neutrophil beta 2 integrin function by inhibiting membraneassociated cyclic gmp synthesis. J Cell Physiol 172(1): 12-24, 1997. PMID: 9207921. DOI: 10.1002/(SICI)1097-4652(199707):1< 12::AID-JCP2>3.0.CO; $2-\mathrm{G}$

32 PeNarando J, Aranda E and RodrIguez-Ariza A: Immunomodulatory roles of nitric oxide in cancer: Tumor microenvironment says "No" To antitumor immune response. Transl Res 210: 99-108, 2019. PMID: 30953610. DOI: 10.1016/j.trs1.2019.03.003

33 Dondoo TO, Fukumori T, Daizumoto K, Fukawa T, Kohzuki M, Kowada M, Kusuhara Y, Mori H, Nakatsuji H, Takahashi M and Kanayama HO: Galectin-3 is implicated in tumor progression and resistance to anti-androgen drug through regulation of androgen receptor signaling in prostate cancer. Anticancer Res 37(1): 125134, 2017. PMID: 28011482. DOI: 10.21873/anticanres.11297

34 Lobo NA, Shimono Y, Qian D and Clarke MF: The biology of cancer stem cells. Annu Rev Cell Dev Biol 23: 675-699, 2007. PMID: 17645413. DOI: 10.1146/annurev.cellbio.22.010305.104154

35 Chang JC: Cancer stem cells: Role in tumor growth, recurrence, metastasis, and treatment resistance. Medicine (Baltimore) 95(1 Suppl 1): S20-25, 2016. PMID: 27611935. DOI: 10.1097/MD.00 00000000004766

36 Zakaria N, Yusoff NM, Zakaria Z, Lim MN, Baharuddin PJN, Fakiruddin KS and Yahaya B: Human non-small cell lung cancer expresses putative cancer stem cell markers and exhibits the transcriptomic profile of multipotent cells. BMC Cancer 15(1): 84, 2015. PMID: 25881239. DOI: 10.1186/s12885-015-1086-3

37 Takahashi K and Yamanaka S: Induction of pluripotent stem cells from mouse embryonic and adult fibroblast cultures by defined factors. Cell 126(4): 663-676, 2006. PMID: 16904174. DOI: $10.1016 /$ j.cell.2006.07.024

38 Czerwińska P, Mazurek S and Wiznerowicz M: Application of induced pluripotency in cancer studies. Rep Pract Oncol Radiother 23(3): 207-214, 2018. PMID: 29760595. DOI: 10.1016/j.rpor.2018.04.005

39 Zeineddine D, Hammoud AA, Mortada M and Boeuf H: The oct4 protein: More than a magic stemness marker. Am J Stem Cells 3(2): 74-82, 2014. PMID: 25232507.
40 Shi G and Jin Y: Role of oct4 in maintaining and regaining stem cell pluripotency. Stem Cell Res Ther 1(5): 39, 2010. PMID: 21156086. DOI: $10.1186 /$ scrt39

41 Hayashi H, Arao T, Togashi Y, Kato H, Fujita Y, De Velasco MA, Kimura H, Matsumoto K, Tanaka K, Okamoto I, Ito A, Yamada Y, Nakagawa K and Nishio K: The oct4 pseudogene pou $5 \mathrm{f} 1 \mathrm{~b}$ is amplified and promotes an aggressive phenotype in gastric cancer. Oncogene 34(2): 199-208, 2015. PMID: 24362523. DOI: $10.1038 / 0$ nc 2013.547

42 Kim R-J and Nam J-S: Oct4 expression enhances features of cancer stem cells in a mouse model of breast cancer. Lab An Res 27(2): 147-152, 2011. PMID: 21826175. DOI: 10.5625/lar.2011.27.2.147

43 Villodre ES, Kipper FC, Pereira MB and Lenz G: Roles of oct4 in tumorigenesis, cancer therapy resistance and prognosis. Cancer Treat Rev 51: 1-9, 2016. PMID: 27788386. DOI: 10.1016/j.ctrv.2016.10.003

44 Karoubi G, Gugger M, Schmid R and Dutly A: Oct4 expression in human non-small cell lung cancer: Implications for therapeutic intervention. Interact Cardiovasc Thorac Surg 8(4): 393-397, 2009. PMID: 19126554. DOI: 10.1510/icvts.2008.193995

45 Tompkins DH, Besnard V, Lange AW, Wert SE, Keiser AR, Smith AN, Lang R and Whitsett JA: Sox 2 is required for maintenance and differentiation of bronchiolar clara, ciliated, and goblet cells. PLoS One 4(12): e8248, 2009. PMID: 20011520. DOI: 10.1371/jounal.pone.0008248

46 Seo E, Basu-Roy U, Zavadil J, Basilico C and Mansukhani A: Distinct functions of sox 2 control self-renewal and differentiation in the osteoblast lineage. Mol Cell Biol 31(22): 4593-4608, 2011. PMID: 21930787. DOI: 10.1128/MCB.05798-11

47 Zhang S, Bell E, Zhi H, Brown S, Imran SAM, Azuara V and Cui W: Oct 4 and pax 6 determine the dual function of sox 2 in human escs as a key pluripotent or neural factor. Stem Cell Res Ther 10(1): 122-122, 2019. PMID: 30999923. DOI: 10.1186/s13287019-1228-7

48 Weina K and Utikal J: Sox 2 and cancer: Current research and its implications in the clinic. Clin Trans Med 3(1): 19, 2014. PMID: 25114775. DOI: 10.1186/2001-1326-3-19

49 Shen L, Huang X, Xie X, Su J, Yuan J and Chen X: High expression of sox 2 and oct 4 indicates radiation resistance and an independent negative prognosis in cervical squamous cell carcinoma. J Histochem Cytochem 62(7): 499-509, 2014. PMID: 24710660. DOI: $10.1369 / 0022155414532654$

50 Elbadawy M, Usui T, Yamawaki H and Sasaki K: Emerging roles of c-myc in cancer stem cell-related signaling and resistance to cancer chemotherapy: A potential therapeutic target against colorectal cancer. Int J Mol Sci 20(9): 2340, 2019. PMID: 31083525. DOI: 10.3390/ijms20092340

51 Zhang H-L, Wang P, Lu M-Z, Zhang S-D and Zheng L: C-myc maintains the self-renewal and chemoresistance properties of colon cancer stem cells. Oncol Lett 17(5): 4487-4493, 2019. PMID: 30944638. DOI: 10.3892/ol.2019.10081

52 Yin S, Cheryan VT, Xu L, Rishi AK and Reddy KB: Myc mediates cancer stem-like cells and emt changes in triple negative breast cancers cells. PloS one 12(8): e0183578-e0183578, 2017. PMID: 28817737. DOI: 10.137/journal.pone.0183578

53 Wang Y, Zhou Y, Tao F, Chai S, Xu X, Yang Y, Yang Y, Xu H and Wang $\mathrm{K}$ : N-myc downstream regulated gene 1(ndrg1) promotes the stem-like properties of lung cancer cells through stabilized c-myc. Cancer Lett 401: 53-62, 2017. PMID: 28456659. DOI: 10.1016/j.canlet.2017.04.031 
54 Ghaleb AM and Yang VW: Kruppel-like factor 4 (klf4): What we currently know. Gene 611: 27-37, 2017. PMID: 28237823. DOI: $10.1016 /$ j.gene.2017.02.025

55 Evans PM and Liu C: Roles of krüpel-like factor 4 in normal homeostasis, cancer and stem cells. Acta Bioch Bioph Sin 40(7): 554-564, 2008. PMID: 18604447. DOI: 10.1111/j.17457270.2008.00439.x

56 Wainwright EN and Scaffidi P: Epigenetics and cancer stem cells: Unleashing, hijacking, and restricting cellular plasticity. Trends Cancer 3(5): 372-386, 2017. PMID: 28718414. DOI:10.1016/j.trecan.2017.04.004

57 Audia JE and Campbell RM: Histone modifications and cancer. CSH Perspect Biol 8(4): a019521-a019521, 2016. PMID: 27037415. DOI: 10.1101/cshperspect.a019521

58 Kulis M and Esteller M: Dna methylation and cancer. Adv Genet 70: 27-56, 2010. PMID: 20920744. DOI: 10.1016/B978-0-12380866-0.60002-2

59 Wang Z-m, Du W-j, Piazza GA and Xi Y: Micrornas are involved in the self-renewal and differentiation of cancer stem cells. Acta Pharm Sin 34(11): 1374-1380, 2013. PMID: 24122008. DOI: 10.1038/aps.2013.134

60 Lien HC, Jeng YM, Jhuang YL and Yuan RH: Increased trimethylation of histone $\mathrm{h} 3 \mathrm{k} 36$ associates with biliary differentiation and predicts poor prognosis in resectable hepatocellular carcinoma. PLoS One 13(10): e0206261, 2018. PMID: 30356299. DOI: 10.1371/journal.pone.0206261

61 Zhang LQ, Li QZ, Jin W, Zuo Y and Guo SC: Genome-wide analysis of $\mathrm{h} 3 \mathrm{k} 36 \mathrm{me} 3$ and its regulations to cancer-related genes expression in human cell lines. Biosystems 171: 59-65, 2018. PMID: 30030162. DOI: 10.1016/j.biosystems.2018.07.004

62 Evanno E, Godet J, Piccirilli N, Guilhot J, Milin S, Gombert JM, Fouchaq B and Roche J: Tri-methylation of h3k79 is decreased in tgf-beta1-induced epithelial-to-mesenchymal transition in lung cancer. Clin Epigenetics 9: 80, 2017. PMID: 28804523. DOI: 10.1186/s13148-017-0380-0

63 Wong M, Polly P and Liu T: The histone methyltransferase dot11: Regulatory functions and a cancer therapy target. Am J Can Res 5(9): 2823-2837, 2015. PMID: 26609488.

64 Kang X, Feng Y, Gan Z, Zeng S, Guo X, Chen X, Zhang Y, Wang C, Liu K, Chen X, Jiang X, Song S, Li Y, Chen S, Sun F, Mao Z, Yang $X$ and Chang J: Nasp antagonize chromatin accessibility through maintaining histone $\mathrm{h} 3 \mathrm{k} 9 \mathrm{me} 1$ in hepatocellular carcinoma. Biochim Biophys Acta Mol Basis Dis 1864(10): 34383448, 2018. PMID: 30076957. DOI: 10.1016/j.bbadis.2018.07.033
65 Maia LL, Peterle GT, Dos Santos M, Trivilin LO, Mendes SO, de Oliveira MM, Dos Santos JG, Stur E, Agostini LP, Couto C, Dalbo J, de Assis A, Archanjo AB, Mercante A, Lopez RVM, Nunes FD, de Carvalho MB, Tajara EH, Louro ID and Alvaresda-Silva AM: Jmjd1a, h3k9me1, h3k9me2 and adm expression as prognostic markers in oral and oropharyngeal squamous cell carcinoma. PLoS One 13(3): e0194884, 2018. PMID: 29590186. DOI: 10.1371/journal.pone.0194884

66 Ali Hosseini Rad SM, Bavarsad MS, Arefian E, Jaseb K, Shahjahani $\mathrm{M}$ and Saki N: The role of microRNAs in stemness of cancer stem cells. Oncol Rev 7(1): e8-e8, 2013. PMID: 25992229. DOI: 10.4081/0ncol.2013.e8

67 Mukai R, Tomimaru Y, Nagano H, Eguchi H, Mimori K, Tomokuni A, Asaoka T, Wada H, Kawamoto K, Marubashi S, Doki Y and Mori M: Mir-615-3p expression level in bone marrow is associated with tumor recurrence in hepatocellular carcinoma. Mol Clin Oncol 3(3): 487-494, 2015. PMID: 26137255. DOI: $10.3892 /$ mco.2015.514

68 Rashid F, Awan HM, Shah A, Chen L and Shan G: Induction of mir-3648 upon er stress and its regulatory role in cell proliferation. Int J Mol Sci 18(7): 1375, 2017. PMID: 28661420. DOI: $10.3390 / \mathrm{ijms} 18071375$

69 Xing R: Mir-3648 promotes prostate cancer cell proliferation by inhibiting adenomatous polyposis coli 2. J Nanosci Nanotechno 19(12): 7526-7531, 2019. PMID: 31196256. DOI: 10.1166/ jnn.2019.16413

70 Sun W, Li S, Yu Y, Jin H, Xie Q, Hua X, Wang S, Tian Z, Zhang $\mathrm{H}$, Jiang G, Huang C and Huang H: Microrna-3648 is upregulated to suppress tcf21, resulting in promotion of invasion and metastasis of human bladder cancer. Mol Ther Nucleic Acids 16: 519-530, 2019. PMID: 31071528. DOI: 10.1016/j.omtn.2019.04.006
Received February 13, 2020

Revised March 11, 2020

Accepted March 13, 2020 